ISSN: 1641-4713; e-ISSN: 2081-1160

DOI: https://doi.org/10.36551/2081-1160.2021.28.1-6

\title{
Memórias em Disputa: Ditaduras e Redemocratizações na América Latina
}

Disputed Memories: Dictatorships and Redemocratizations in Latin America

Izabel Pimentel da Silva Universidade do Estado do Rio de Janeiro (UERJ-FFP/ Brasil) ID ORCID: https://orcid.org/0000-0003-0991-5322

Email: belprisk@hotmail.com

Samantha Viz Quadrat Universidade Federal Fluminense (UFF/ Brasil) ID ORCID: https://orcid.org/0000-0003-1547-1000 Email: samantha.quadrat@gmail.com

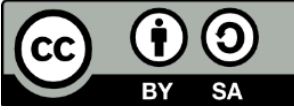

A segunda metade do século XX foi marcada na América Latina, em especial na região do Cone Sul, pela emergência de governos autoritários liderados pelas Forças Armadas, que em maior ou menor medida possuíam um papel de destaque na arena política latino-americana. Contando com o apoio de amplos setores civis, estes militares implantaram e sustentaram ditaduras, que tinham como característica central um alto e intenso grau de violência política. Nesse sentido, tais governos, frutos da Guerra Fria e das disputas internas dos próprios países, iriam perseguir, cassar, censurar, prender, banir e matar as vozes dissidentes e seus opositores políticos.

Com o fim das ditaduras, os países latino-americanos - cada um com sua temporalidade e características específicas - passaram pelo complexo processo 
de redemocratização, que refletia as tensões, embates e negociações dos atores políticos envolvidos. Inseridos em conjunturas políticas distintas e condicionados pela correlação de forças dos grupos políticos nacionais, os países latino-americanos tiveram que enfrentar o desafio de lidar com seu passado autoritário e com as demandas de reparações das violações dos direitos humanos cometidas durante as ditaduras, no bojo do que ficou conhecido como Justiça de Transição.

$\mathrm{Na}$ medida em que as sociedades latino-americanas iam reconstruindo suas democracias, também se iniciava o processo de disputa de memórias das ditaduras e redemocratizações. Esse constante processo de (re)construção do passado tem sido baseado, sobretudo, nos depoimentos e testemunhos de ex-militantes políticos, que se tornaram uma das fontes preferenciais para os historiadores. A explosão de narrativas memorialísticas e os discursos testemunhais estão articulados aos usos políticos do passado e aos embates do presente no campo político, ideológico e historiográfico. Nesse sentido, ao historiador tem sido lançado o desafio de compreender as leituras do passado que as memórias coletivas empreendem.

O presente dossiê, publicado no número 28 da Revista del CESLA. International Latin American Studies Review, reúne 14 artigos escritos em português, espanhol e inglês por pesquisadoras e pesquisadores de diferentes gerações e distintos países que analisam, por variadas perspectivas, as ditaduras e processos de redemocratizações vivenciados pelos países latino-americanos ao longo da segunda metade do século XX.

Utilizando distintas fontes escritas e orais e contemplando os debates sobre Argentina, Brasil, Bolívia, Chile, Paraguai e Uruguai, os textos analisam as estruturas burocrático-militares, os mecanismos de repressão e projetos autoritários das ditaduras na América Latina; as relações entre sociedade civil e Estado durante regimes autoritários; os projetos de resistências às ditaduras e a atuação dos movimentos sociais; a experiência do exílio e as dificuldades do retorno e inserção em um contexto de transição à democracia; os distintos caminhos do complexo processo de redemocratização e os mecanismos de Justiça de Transição nos países latino-americanos; o papel dos testemunhos na denúncia dos crimes de violação dos Direitos Humanos; a construção de memórias e narrativas acerca das ditaduras e redemocratizações na América Latina; as políticas públicas de memória; a criação dos chamados lugares de memória e as disputas políticas e sociais envolvidas nas (re)construções de novos sentidos para o passado e seus usos políticos.

O dossiê se inicia com o artigo de Natalia García, que analisa as atas secretas da Junta Militar Argentina, definida como o órgão máximo responsável 
pelo terrorismo de Estado durante os anos de 1976 a 1983. No texto, a autora discute, a partir desse fundo documental, as dinâmicas internas da Junta Militar, seu caráter fundacional e os temas que foram priorizados em sua agenda, incluindo a planificação sistemática da repressão ilegal do Estado.

A repressão desencadeada durante a última ditadura na Argentina também é abordada no texto de Paula Vera Canelo. Em seu artigo, a autora analisa o processo de militarização do recrutamento dos intendentes, as autoridades máximas municipais, na província de Buenos Aires, apontando as relações intrínsecas entre os objetivos políticos e governamentais e os objetivos repressivos da ditadura argentina.

Para além da análise da repressão característica das ditaduras latino-americanas, a historiografia contemporânea também tem destacado as complexas relações entre Estado e sociedade durante regimes autoritários. Nesse sentido, o artigo de Pedro Henrique Pedreira Campos se debruça sobre o processo de internacionalização das empreiteiras brasileiras, destacando o papel do Itamaraty e da diplomacia brasileira e as relações entre órgãos estatais e empresas privadas durante a ditadura no Brasil.

O dossiê prossegue com dois artigos sobre a Bolívia, país que tem ganhado destaque nos últimos anos nas publicações sobre ditaduras na América Latina, especialmente na sua relação com os demais governos autoritários através do que chamamos Plano Condor, assim como a construção do Estado repressor e as formas de resistência de setores da sociedade boliviana. Dessa maneira, o texto de Guilherme de Moraes Andrade aborda como diferentes setores do mundo do trabalho se relacionaram com a ditadura e se dividiram entre o apoio e a resistência, assim como os sucessivos governos autoritários a partir de 1964 procuram construir um consenso ao seu redor. Reynaldo Tapia, por sua vez, aborda em seu texto a resistência civil a essas ditaduras. Em seu artigo é possível conhecer as estratégias sem uso da violência e sua efetividade para a construção democrática boliviana.

A historiografia contemporânea sobre as ditaduras e redemocratizações na América Latina tem cada vez mais valorizado os depoimentos e testemunhos, coletados a partir da metodologia da História Oral, como fontes importantes para as discussões acerca da violência política das ditaduras e do papel do testemunho de catástrofes e/ou experiências traumáticas. Estes testemunhos nos permitem compreender a construção das estratégias de ação e das representações dos grupos ou indivíduos em diferentes contextos. E ainda: os depoimentos colocam em 
evidência as memórias, os silêncios, as trajetórias, as experiências de vida e as subjetividades.

$\mathrm{O}$ artigo de Marcos Tolentino analisa os usos dos testemunhos como estratégia de denúncia da violência estatal na Argentina durante a última ditadura, discutindo suas lógicas de produção e circulação na Argentina, bem como o papel dos organismos de Direitos Humanos e a atuação das organizações de familiares de desaparecidos políticos, que foram algumas das primeiras vozes que, ainda nos primeiros anos da ditadura e no auge da repressão, denunciaram a violência do Estado.

Os testemunhos dos sobreviventes foram fundamentais não só para a abertura de processos judiciais contra agentes que cometeram crimes de violação dos Direitos Humanos na ditadura argentina, mas também no reconhecimento e mapeamento de espaços onde ocorreram graves violações de Direitos Humanos ou que foram referências, seja para a resistência ou para a própria ditadura.

$\mathrm{O}$ artigo de Lisandro Cañón debate esses lugares de memória, mais especificamente os espaços de repressão - que posteriormente foram convertidos em provas judiciais nos julgamentos das Juntas Militares - e as memórias construídas pelos sobreviventes desses espaços, cujos testemunhos contribuíram para uma radiografia do terrorismo de Estado na Argentina e para as lutas por verdade, memória e justiça.

As políticas públicas de memória, que incluem a identificação e recuperação dos lugares de memória na América Latina, são também oriundas das pressões exercidas pela sociedade por meio de grupos de direitos humanos e/ou atingidos direta ou indiretamente pela ação das ditaduras, com o intuito de promover o que chamamos de dever de memória para com as vítimas. Esse processo não é isento de embates políticos e sociais, disputas de memórias e (re)construções de novos sentidos para o passado e seus usos políticos.

Essa é a temática discutida no artigo de Marina Maria de Lira Rocha, a partir da análise da construção do Museo de las Memorias, localizado em Assunção, capital do Paraguai, no antigo prédio de um órgão do sistema repressivo da longa ditadura de Alfredo Stroessner. A autora discute as transformações nas narrativas do museu, seu papel pedagógico e as (re)construções das memórias acerca da ditadura no Paraguai.

Também partindo do caso do Paraguai, o artigo de Luis Roniger, Leonardo Senkman, Saúl Sosnowski e Mario Sznajder coloca em evidência outra importante faceta vivenciada durante as ditaduras na América Latina: a experiência do exílio, que foi institucionalizado, ao lado das prisões, execuções e desapareci- 
mentos políticos, como mecanismo para afastar e/ou desarticular elementos considerados "subversivos", que desafiavam os regimes autoritários. Através de entrevistas realizadas pelos autores no Paraguai, o texto nos permite acompanhar distintas trajetórias e desafios enfrentados pelos paraguaios no exílio, as resistências à ditadura no exterior e as dificuldades no retorno ao país, ainda durante a ditadura e ao longo do processo de transição à democracia.

$\mathrm{O}$ dossiê termina com um bloco de artigos que se ocuparam em refletir sobre a redemocratização e a atuação de diversos setores sociais frente aos desafios dos novos tempos. São reflexões profundas sobre novos atores, demandas que muitas vezes enfrentaram resistências mesmo em um momento em que a democracia e o futuro que queríamos eram o centro do debate em países recémsaídos das ditaduras.

Marcial Humberto Saavedra de Castro e Lina Maria Brandão de Aras se voltam para um tema fundamental desse período que é o papel das Forças Armadas na retirada do poder, mas não da arena política. Nesse sentido, ao analisarem o caso do Chile apontam as especificidades chilenas, como a manutenção de uma Constituição herdada da ditadura, assim como a retomada da sociedade organizada ao espaço público até então dominado por políticos civis e militares.

$\mathrm{Na}$ perspectiva de futuro, dois grupos se apresentaram nesse momento. A participação de mulheres e feministas na transição chilena é analisada por Claudia Maldonado Salazar. Como demonstra a autora, o Chile foi um país onde a ditadura se dirigiu particularmente às mulheres, cujo alguns grupos foram importantes no golpe de 11 de setembro de 1973. A autora historiciza a ação da ditadura e também das mulheres e feministas, em especial o grupo da Concertación de Mujeres por la Democracia, a partir dos anos 1980, com suas demandas e contribuições ao fim da ditadura e à democracia. No caso uruguaio, Diego Sempol contribui aos estudos sobre juventude e transição democrática ao analisar a censura à exposição de Óscar Larroca, em 1986, e o processo e prisão de Esteban de Armas, após uma apresentação da banda de rock Clandestinos, na qual ele era o vocalista, em 1988. Em jogo na análise as experimentações juvenis, a questão comportamental e a reação às demandas e questionamentos de uma nova geração. Em ambos os textos ficam claras as tensões e pressões que esses grupos promoveram com suas ações no cenário público, empurrando os limites da democracia em construção.

Por fim, o dossiê encerra com dois artigos que analisam as incertezas sobre a democracia e sua instabilidade na América Latina. Janeth Hernández Flores aborda não apenas um país, mas a situação latino-americana atual e o uso de 
novos mecanismos que atentam contra o Estado democrático de Direito. Fernanda Abreu Silva, por sua vez, aborda o enfrentamento entre políticas de memória e políticas de silenciamento sobre o passado ditatorial brasileiro no qual a lei de anistia (1979) assume o papel de protagonista no debate público no que diz respeito às ações de memória, verdade e justiça.

Esperamos que o conjunto de artigos aqui reunidos contribuam não apenas para o debate historiográfico, mas também para o fortalecimento democrático em um momento no qual a extrema direita voltou a ocupar nos últimos anos um papel de destaque em alguns dos países aqui analisados, assim como a disputa da narrativa sobre o passado ditatorial. 